\title{
Optimal Selection of Distributed Energy Resources under Uncertainty and Risk Aversion
}

\author{
Lajos Maurovich-Horvat* Bert De Reyck ${ }^{\dagger} \quad$ Paula Rocha $^{\ddagger}$ \\ Afzal Siddiqui* $\S$
}

\begin{abstract}
The adoption of small-scale electricity generation has been hindered by uncertain electricity and gas prices. In order to overcome this barrier to investment, we develop a mean-risk optimisation model for the long-term risk management problem of an energy consumer using stochastic programming. The consumer can invest in a number of generation technologies and also has access to electricity and gas futures to reduce its risk. We examine the role of on-site generation in the consumer's risk management strategy as well as interactions between on-site generation and financial hedges. Our study shows that by swapping electricity (with high price volatility) for gas (with low price volatility), even relatively inefficient technologies reduce risk exposure and $\mathrm{CO}_{2}$ emissions. The capability of on-site generation is enhanced through the use of combined heat and power (CHP) applications. In essence, by investing in a CHP unit, a consumer obtains the option to use on-site generation whenever the electricity price peaks, thereby reducing its financial risk. Finally, in contrast to the extant literature, we demonstrate that on-site generation affects the consumer's decision to purchase financial hedges. In particular, while on-site generation and electricity futures may act as substitutes, on-site generation and gas futures can function as complements.
\end{abstract}

\section{Managerial Relevance Statement}

Price volatility typically deters investment in most industries. For example, uncertain demand after 2008 led many automobile manufacturers to postpone their expansion plans. Likewise, in the energy sector, investment in generation technologies by building owners has failed to meet government targets primarily because of highly volatile electricity and natural gas prices. In order to facilitate technology adoption by a large consumer that can install on-site generation, we use an approach that allows for hedging against risk from volatile prices. We focus on how on-site generation interacts with financial hedges, i.e., how the availability of technology affects the consumer's decision to use financial hedges and vice

${ }^{*}$ Department of Statistical Science, University College London, United Kingdom

${ }^{\dagger}$ School of Management, University College London, United Kingdom

${ }_{\ddagger}^{\ddagger}$ Department of Statistical Science, University College London, United Kingdom

${ }^{\S}$ Department of Statistical Science, University College London, United Kingdom and Department of Computer and Systems Sciences, Stockholm University, Sweden 
versa. In particular, we find that since investing in combined heat and power applications reduces the consumer's demand for electricity futures, on-site generation and electricity futures may substitute for one another. Conversely, when gas futures are available, the consumer is more likely to install on-site generation because a fixed fuel price results in larger risk reduction, thereby indicating that gas futures and on-site generation can function as complements. Hence, we develop an optimal investment and hedging strategy to facilitate technology adoption by a risk-averse consumer facing volatile prices. 


\section{Introduction}

Climate change has emerged as one of the most contentious and critical issues of our time. Its probable severe economic and environmental consequences have prompted many countries to set a series of targets to reduce their $\mathrm{CO}_{2}$ emissions [1]. For example, the European Union (EU) aims to reduce its greenhouse gas emissions by $20 \%$ by 2020 and by $85-90 \%$ by 2050 compared to 1990 levels [2].

One of the ways in which the EU seeks to achieve these targets is by improving energy efficiency in terms of both supply and consumption [3]. There is substantial scope for reducing $\mathrm{CO}_{2}$ emissions through improved generation technologies. The current central-station model of electricity production leads to energy losses of $35-60 \%$ as heat waste, and a further $6 \%$ of generated electricity is lost during transmission. 1 Thus, the current paradigm is not only polluting but also unsustainable in the presence of continued demand growth. One possible solution is the use of distributed energy resources (DER), which are small-scale generation sources located closer to end-users. This way, waste heat can also be captured and utilised to meet local heating demands in buildings or to generate mechanical energy in manufacturing. Such combined heat and power (CHP) applications can increase overall energy efficiency at any location requiring both electricity and heat. For example, the presence of city-wide district heating schemes enables Denmark to supply $80 \%$ of its heat demand through cogeneration, thereby becoming one of the most energy-efficient countries in the world [4].

Although policymakers have set ambitious targets, technology-adoption decisions are typically made by power companies and large consumers, e.g., residential estates, office buildings, and factories. Since the late 1980s, policymakers have gradually deregulated power sectors with the intention of increasing competition between producers [5]. Consequently, the 1990s saw the introduction of several directives from the EU that sought to extend the single market principle to the electricity industry [6]. However, deregulation often resulted in flawed

\footnotetext{
${ }^{1}$ http://www.eia.gov/tools/faqs/faq.cfm $? \mathrm{id}=105 \& \mathrm{t}=3$
} 
market designs, which led to market power abuse and spot price volatility [7]. In addition, in Europe, the increased share of intermittent generation resulted in more frequent price jumps and negative electricity prices, while the gas price has been affected by political uncertainties. As a result of such policy changes and market uncertainties, energy producers and consumers face increased exposure to financial risk, which hampers their investment decisions precisely when new technologies are required to replace inefficient and unsustainable ones.

Considering this situation, in order to gain policy insights about increasing efficiency and reducing $\mathrm{CO}_{2}$ emissions, it is important to understand how the risk associated with electricity and gas spot price uncertainty can be managed at the consumer level. With this in mind, we explore the roles of on-site generation as a physical hedge and electricity and gas futures contracts as financial hedges against energy price risk. Specifically, we demonstrate that risk-averse consumers, even if they face increasing gas prices and decreasing electricity

prices, should invest in on-site generation. In accounting for risk, we show that the ability of CHP to swap electricity (with high price volatility) for gas (with low price volatility) increases the value of on-site generation as a physical hedge significantly. Finally, we examine how onsite generation interacts with financial hedges, i.e., how the availability of on-site generation affects the consumer's decision to purchase financial hedges and vice versa. In particular, we find that, while on-site generation and electricity futures may substitute one another, on-site generation and gas futures can function as complements.

\section{Literature Review}

The benefits of on-site generation and CHP have been analysed using deterministic, real options, and stochastic programming approaches. From a deterministic approach, the economic adoption and diffusion of CHP generation is examined in [8] using net present value (NPV) calculations. Siddiqui et al. [9] compare the economic benefit of installing different types of DER at a hypothetical microgrid in California. Using mixed-integer linear program- 
ming, they demonstrate that an optimally run microgrid with gas-fired CHP turbines has, on average, lower $\mathrm{CO}_{2}$ emissions than microturbines without heat exchangers. Expanding on [9], [10] analyses the conditions under which a microgrid with CHP is profitable, particularly when also equipped with heat storage technology. Thus, such deterministic approaches have the advantage that they account for the detailed thermodynamics at the building level over a fine time resolution. However, these deterministic models ignore uncertainty in electricity and fuel prices, which means that they are unable to assess the impact of risk exposure on DER adoption and sizing.

Addressing uncertain electricity prices, [12] applies real options valuation to investments in decentralised renewable power generation. Results from a case of wind power generation for an office building suggest that, within the context of uncertain electricity prices, the threshold price for investment is higher than the NPV break-even price. Maribu and Fleten [13] use Monte Carlo simulation to show that cogeneration is particularly attractive with volatile electricity prices because the CHP plant's ability to respond to high prices provides efficient hedges to energy cost risk. Using a similar approach, [11] determines that the adoption of small-scale distributed generation has been slow because uncertainty in future energy prices represents significant economic risk and suggests feed-in tariffs for its mitigation. Analysing an industrial firm's choice, [14] finds that under higher price volatility levels, it is more profitable to invest in a CHP system than in a conventional heat-only generation. Siddiqui and Maribu [15] examine the effects of a sequential strategy on the investment of a microgrid when capacity and heat exchanger upgrade options are available. They conclude that a direct investment strategy is preferred with a combined distributed generation and heat exchange system compared to the sequential strategy due to the cost savings from heat production and capture. Thus, the real options approach allows for the possibility of stochastic prices in not only assessing the value of waiting but also determining the optimal threshold price for investment. However, with rare exceptions, e.g., [16], the real options approach does not directly tackle risk reduction. 
By contrast, stochastic programming facilitates risk management as it can provide robust solutions over worst-case scenarios [17, 18] even with tail-dependent dependence structures [19]. Since the deregulation of the electricity industry, stochastic programming has been widely applied within the power sector. Fleten and Kristoffersen [20] compare stochastic programming and deterministic approaches in devising bidding strategies of a Norwegian hydropower producer. They find that using a stochastic programming model yields, on average, more profitable configurations than using a deterministic approach while improving robustness. Carrión et al. [21] use stochastic programming to model cost minimisation of a large risk-averse energy consumer with on-site generation. They discuss the tradeoffs associated with bilateral contracts, self-production, and purchasing electricity from the pool. A multi-stage stochastic optimisation model is developed by [22] to analyse the impact of carbon price uncertainty on investments in the energy sector. However, a disadvantage of the stochastic programming approach is that the computational requirements increase exponentially with the complexity of the problem being analysed. In order to cope with these limitations of stochastic programming, [23] provides scenario-reduction and formulation techniques.

We apply stochastic programming to the investment problem of a large consumer, which has been examined previously using only deterministic models and real options. While a similar perspective is taken in [21], our model also incorporates uncertain gas prices in addition to uncertain electricity prices. Furthermore, we allow for the possibility of heat recovery by a CHP application and examine the associated investment decision, which is not considered by [21] in their purely operational model. More important, we examine the options of investing in on-site generation and entering into electricity and gas futures contracts in the same model. 


\section{Model Description}

Our model addresses the investment problem of a hypothetical commercial consumer with electricity and heat loads. Initially, the consumer owns only a gas-fired boiler, but it has the option to invest in various-sized gas-fired microturbines, with or without heat exchangers, at the beginning of the time horizon. If this option is not exercised, then the consumer can meet its electricity loads only through purchasing electricity on the spot and futures markets. Similarly, the consumer covers all of its heat loads by purchasing gas on the spot and futures markets for its boiler. Unless otherwise indicated, we assume that both electricity and gas and futures contracts are physically settled. If a microturbine without a heat exchanger is installed, then the consumer can meet (part of) its electricity demand with on-site generation, for which the gas is purchased on the spot and futures markets. If CHP is installed, then the consumer also has the possibility to recover the heat waste from its electricity generation and utilise it to supply (part of) its heat loads (see Fig. 1).

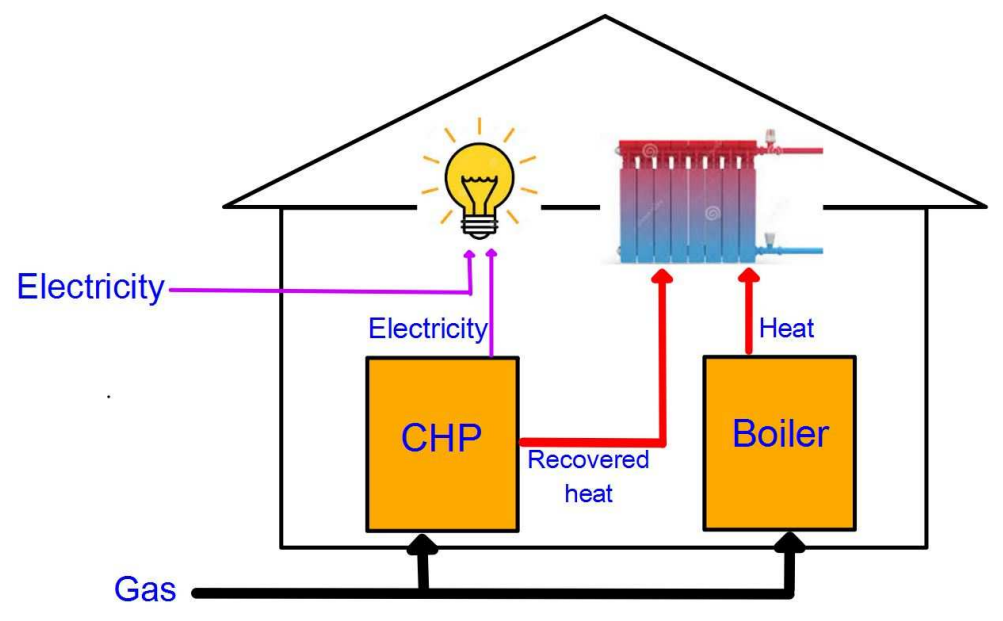

Figure 1: Energy system of a consumer with CHP

We assume that the consumer is a price taker and that it faces uncertain electricity and gas spot prices. By contrast, since energy loads in commercial buildings can be forecast accurately [24], we assume that both electricity and heat loads are known in advance. Likewise, technology costs are assumed to be fixed in real terms as our focus is on managing 
the risk from uncertain prices (see [25] for incorporation of technology cost risk). Thus, the consumer makes its investment and futures contracting decisions without knowing spot price realisations, but it can purchase additional electricity and gas later, when their spot prices are known. Therefore, the consumer's investment problem can be formulated as a linear mixed-integer multi-stage stochastic program with recourse. To take into account possible risk preferences, we assume that the consumer's objective is to minimise its expected cost plus a penalised risk measure with weight $B$. For the risk measure, we use the conditional value-at-risk $(\mathrm{CVaR})$, which estimates the expected loss with a confidence level $A \in[0,1)$ in the worst $(1-A) \times 100 \%$ cases. CVaR is a coherent risk measure [26], and, as it can be formulated using linear programming, it is suitable for optimisation problems [27]. Intuitively, for $A=0.95$, the $\mathrm{CVaR}$ is the expected discounted cost given that we are in the $5 \%$ worst scenarios. Finally, we examine different regimes for the consumer in terms of risk aversion, such as $B=0$ for a risk-neutral regime and $B>0$ for a risk-averse regime.

\subsection{Decision-Making Framework}

The time horizon of the optimisation problem is divided into main periods indexed by $t \in \mathcal{T}:=\{1, \ldots, T\}$, each of which is split into subperiods, indexed by $m \in \mathcal{M}:=$ $\{1, \ldots, M\}$, of equal length (see Fig. 2). The decision to invest in on-site generation has to be made at the beginning of the first main period, i.e., at $t=1$, without knowledge of the long-term price realisations and is effective immediately. At the beginning of every main period, the consumer can reduce its risk exposure by purchasing electricity and gas futures for physical delivery at a constant rate in each subperiod of that main period. Subsequently, the consumer can adjust its futures purchases by going on the spot market to purchase elec-

tricity and gas at their realised prices in each subperiod within that main period. These futures decisions are made under uncertainty, in this case regarding the short-term price realisations. Similarly, the consumer also decides in each subperiod how much electricity to generate and how to meet its heat demand. The decision-making timeline is necessarily 
stylised with the representation of quarterly time steps for making operational adjustments or annual ones for purchasing futures contracts as justified in Section 4.1 with discussion of scenario generation in Appendix B. Finer resolution of both types of decisions would be more realistic but at the expense of greater computational time.

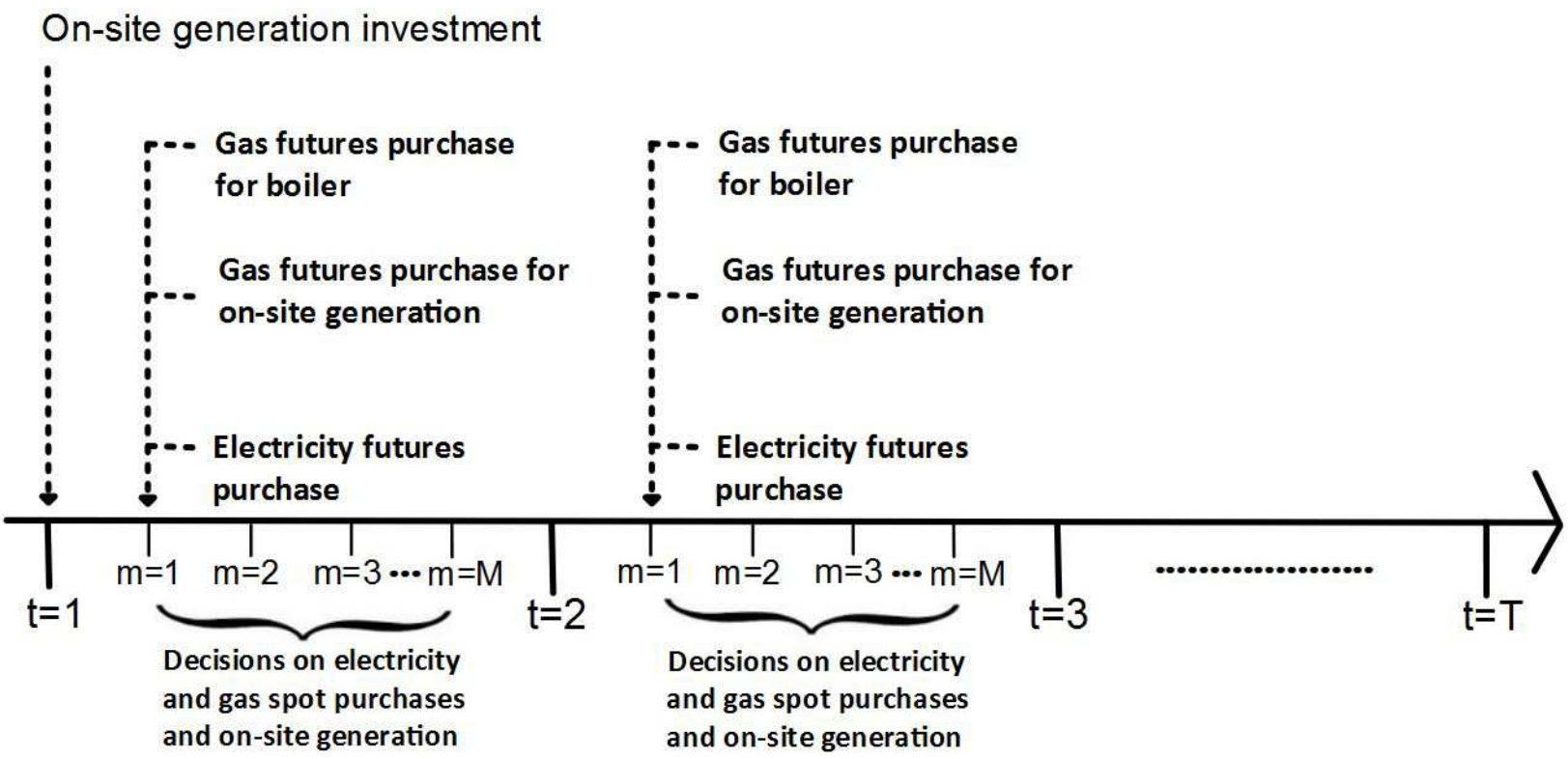

Figure 2: Decision-making timeline

\subsection{Mathematical Formulation}

The consumer's investment problem is formulated as a mixed-integer stochastic program, in which the goal is to minimise the expected present value of its cost plus the CVaR with $B$ weight. The uncertain price processes are represented through a scenario tree (with nodes) combined with a scenario fan (with subscenarios) per node. The model's notation and a detailed description of the scenario generation method are presented in Appendices $\mathrm{A}$ and B. respectively. An essential part of the problem formulation in stochastic programming models is the implementation of the non-anticipativity principle, i.e., decisions need to be taken without knowing in advance the future outcomes. Therefore, the investment decision, $w_{i}, i \in \mathcal{I}$, is the same in every node and subscenario, whereas the futures purchase decisions, $x_{n}^{\mathrm{f}}, y_{i, n}^{\mathrm{f}}$, and $z_{n}^{\mathrm{f}}$, are the same for each subscenario at a given node $n \in \mathcal{N}$. By fixing these 
decision variables and certain parameters, we can also explore various cases in which financial or physical hedging is not allowed. For example, fixing $w_{i}=0, \forall i, x_{n}^{\mathrm{f}}=0, \forall n, y_{i, n}^{\mathrm{f}}=0, \forall i, n$, and $z_{n}^{\mathrm{f}}=0, \forall n$ corresponds to a case in which the consumer must procure all energy on the spot market. Similarly, fixing $x_{n}^{\mathrm{f}}=0, \forall n, y_{i, n}^{\mathrm{f}}=0, \forall i, n$, and $z_{n}^{\mathrm{f}}=0, \forall n$ corresponds to a

case in which only physical hedging is allowed. Finally, setting the parameter $E_{i}^{\mathrm{h}}=0, \forall i$ allows us to investigate cases without CHP but with MT and financial hedging.

\subsubsection{Objective Function}

The objective function (1) minimises the sum of the expected value and a weighted CVaR of the present value of the consumer's cumulative costs, where $Q_{n}$ is the probability of node $n$ :

$$
\operatorname{minimise} \sum_{n \in \mathcal{N}_{T}} Q_{n} \gamma_{n}+B\left(\xi+\frac{1}{1-A} \sum_{n \in \mathcal{N}_{T}} Q_{n} \eta_{n}\right)
$$

This weighted average in Eq. (1) allows us to explore not only risk-neutral but also risk-averse consumers. Indeed, the risk from volatile energy prices may be a deterrent for potential adopters of DER. Thus, we are not restricted to examining only the admittedly unrealistic objective of minimising expected costs.

\subsubsection{Constraints}

Eqs. (2a) -(2b) define the CVaR constraint of the present value of the cumulative cost of running the consumer's energy system, $\forall n \in \mathcal{N}_{T}$. Intuitively, the objective function in Eq. (11) aims to make the non-negative variable, $\eta_{n}$, as small as possible. Here, $\xi$ represents the $A \times 100 \%$ quantile of the present value of the cumulative cost, i.e., the value-at-risk (VaR). In nodes with $\gamma_{n} \leq \xi, \eta_{n}$ is driven to zero, i.e., the present value of the cumulative cost at node $n$ is less than the VaR. However, in nodes with $\gamma_{n}>\xi, \eta_{n}>0$ represents precisely the excess in the present value of the cumulative cost over $\xi$ at node $n$. Hence, weighting $\eta_{n}$ by probability $Q_{n}$ in Eq. (11), summing up over all $n$ in the terminal main period, and scaling 
by the $\frac{1}{1-A}$ term yields the expected excess in the present value of cumulative costs relative to $\xi$, which is just the CVaR once $\xi$ is added:

$$
\begin{gathered}
\gamma_{n}-\xi-\eta_{n} \leq 0 \\
\eta_{n} \geq 0
\end{gathered}
$$

Eq. (3) updates the present value of the cumulative cost of energy provision, $\forall n \in \mathcal{N}$, as the present value of the cumulative cost in the preceding node plus the discounted expected amortised capital, futures, and spot operational costs incurred within that main period's subperiods:

$$
\gamma_{n}= \begin{cases}\varpi_{n}+\Phi_{n} & \text { if } n \in \mathcal{N}_{1} \\ \gamma_{b(n)}+(1+R H)^{-(t(n)-1) M}\left(\varpi_{n}+\Phi_{n}\right) & \text { otherwise }\end{cases}
$$

Eq. (4) calculates the expected present value at the beginning of the main period $t(n)$ for all spot operational and amortised capital cost within that main period, $\forall n \in \mathcal{N}$ :

$$
\varpi_{n}=\sum_{s \in \mathcal{S}} Q_{s}^{\mathrm{s}}\left(\sum_{m \in \mathcal{M}}(1+R H)^{-m}\left(\Psi+\Omega_{n, s, m}\right)\right)
$$

Eqs. (5) -(17) give the amortised capital, futures, and spot operational costs, respectively, $\forall n \in \mathcal{N}, \forall s \in \mathcal{S}, \forall m \in \mathcal{M}:$

$$
\begin{gathered}
\Psi=\sum_{i \in \mathcal{I}} w_{i} N_{i} \\
\Phi_{n}=\sum_{i \in \mathcal{I}}\left(F_{n}^{\mathrm{g}}+V^{\mathrm{e}}+L^{\mathrm{c}} C\right) y_{i, n}^{\mathrm{f}}+F_{n}^{\mathrm{e}} x_{n}^{\mathrm{f}}+\left(F_{n}^{\mathrm{g}}+L^{\mathrm{c}} C\right) z_{n}^{\mathrm{f}} \\
\Omega_{n, s, m}=\sum_{i \in \mathcal{I}}\left(P_{n, s, m}^{\mathrm{g}}+V^{\mathrm{e}}+L^{\mathrm{c}} C\right) y_{i, n, s, m}+P_{n, s, m}^{\mathrm{e}} x_{n, s, m}+\left(P_{n, s, m}^{\mathrm{g}}+L^{\mathrm{c}} C\right) z_{n, s, m}
\end{gathered}
$$

Eqs. (8) -(9) ensure that the electricity and heat demands are met, respectively, $\forall n \in \mathcal{N}, \forall s \in$ $\mathcal{S}, \forall m \in \mathcal{M}$. For example, Eq. (8) states that the electricity purchased from the spot market and the futures market plus that generated on-site (using fuel procured from either the spot or the futures market) must at least equal the electricity demand. Likewise, Eq. (9) requires the total heat available from CHP plus the boiler (again using fuel from either the spot or 
the futures market) to meet the heat demand:

$$
\begin{gathered}
x_{n, s, m}+\frac{x_{n}^{\mathrm{f}}}{M}+\sum_{i \in \mathcal{I}} E_{i}^{\mathrm{e}}\left(y_{i, n, s, m}+\frac{y_{i, n}^{\mathrm{f}}}{M}\right) \geq D^{\mathrm{e}} H J \\
\sum_{i \in \mathcal{I}} h_{i, n, s, m}+E^{\mathrm{b}}\left(z_{n, s, m}+\frac{z_{n}^{\mathrm{f}}}{M}\right) \geq D^{\mathrm{h}} H J
\end{gathered}
$$

Eq. (10) restricts the use of recovered heat, $\forall i \in \mathcal{I}, \forall n \in \mathcal{N}, \forall s \in \mathcal{S}, \forall m \in \mathcal{M}$, where $E_{i}^{\mathrm{h}}$ represents the heat capture rate of technology $i$ :

$$
h_{i, n, s, m} \leq E_{i}^{\mathrm{h}} E_{i}^{\mathrm{e}}\left(y_{i, n, s, m}+\frac{y_{i, n}^{\mathrm{f}}}{M}\right)
$$

Eqs. (11)-(12) ensure that the CHP and boiler capacity limits are observed, respectively, $\forall n \in \mathcal{N}, \forall s \in \mathcal{S}, \forall m \in \mathcal{M}$, where $E_{i}^{\mathrm{e}}$ and $E^{\mathrm{b}}$ represent the electrical conversion efficiency of technology $i$ and the boiler conversion efficiency, respectively:

$$
\begin{gathered}
E_{i}^{\mathrm{e}}\left(y_{i, n, s, m}+\frac{y_{i, n}^{\mathrm{f}}}{M}\right) \leq w_{i} K_{i}^{\mathrm{e}} H J, \forall i \in \mathcal{I} \\
E^{\mathrm{b}}\left(z_{n, s, m}+\frac{z_{n}^{\mathrm{f}}}{M}\right) \leq K^{\mathrm{b}} H J
\end{gathered}
$$

Finally, all decision variables must be non-negative, $\forall i \in \mathcal{I}, \forall n \in \mathcal{N}, \forall s \in \mathcal{S}, \forall m \in \mathcal{M}$ :

$$
w_{i} \in\{0,1\}, x_{n, s, m} \geq 0, y_{i, n, s, m} \geq 0, z_{n, s, m} \geq 0, x_{n}^{\mathrm{f}} \geq 0, y_{i, n}^{\mathrm{f}} \geq 0, z_{n}^{\mathrm{f}} \geq 0
$$

\section{Numerical Examples}

\subsection{Data and Cases}

While Europe has a relatively high level of CHP production, with Denmark, Finland, and the Netherlands having some of the highest rates of cogeneration in the world, the potential for further CHP implementation is substantial. Golbach [28] estimates that over 50\% of Germany's total electricity demand could be provided through CHP. Accordingly, Germany has passed three different legislations since 2002 promoting the adoption of CHP with the aim to increase its rate of cogeneration from the current level of $14.5 \%$ to $25 \%$ by 2020 [29]. 
However, due to factors like uncertain fuel prices and economic stagnation, the trajectory of CHP adoption relative to the $25 \%$ target has been unsatisfactory during the past few years.

In order to examine the risk exposure of a hypothetical consumer with CHP and study ways to mitigate it, we implement a case study using German data. Due to its climate and EU policy, northern Europe is an ideal testbed for CHP expansion. We solve the resulting optimisation problem over a time horizon of eight years, incorporating four main periods, with eight subperiods per main period. Each main period, therefore, covers two years, while a subperiod covers a quarter. We illustrate the effect of physical and financial hedges on the decision-making process through several cases, which differ in terms of available hedges (Table 1). As noted in Section 3.2, these cases are generated by simply forcing appropriate decision variables and parameters to be zero. Thus, if financial or physical hedges are allowed, then their sizes or quantities are also decision variables. The impact of risk aversion is captured by varying the $B$ parameter.

The microturbine parameters (Table 2) are collected from [11], 30], and [31]. We consider microturbines without CHP (MT) and microturbines with CHP (MT-CHP) of different capacity sizes. The results have not been validated at a real site because it is generally not possible to advise a consumer to switch its energy procurement strategy and to observe the subsequent changes in costs. However, [25] did validate the performance of stochastic programming tools for technology adoption and operation by real buildings. In particular, the observed energy consumption and cost patterns of a Spanish test site are faithfully replicated by the model when it is run by an independent energy auditor for only the current year with investment decisions disabled.

We estimate spot price parameters using data from the European Energy Exchange's (EEX) German electricity and gas markets, while Phelix and Natural Gas Futures markets data from 2007-2012 are used for estimating price parameters for the financial contracts (Table 3). Risk premia for electricity and gas futures are calculated using two-yearly futures since each main period consists of two years. 
Table 1: Consumer's hedging cases

\begin{tabular}{|l|c|c|c|}
\hline Case & $\begin{array}{l}\text { Electricity } \\
\text { futures }\end{array}$ & $\begin{array}{l}\text { Gas } \\
\text { futures }\end{array}$ & $\begin{array}{l}\text { DER } \\
\text { investment }\end{array}$ \\
\hline 1 - No hedges & X & & \\
\hline 2 - Electricity futures only & $\mathrm{X}$ & $\mathrm{X}$ & \\
\hline 3 - Gas futures only & $\mathrm{X}$ & $\mathrm{X}$ \\
\hline 4 - Both futures & & & $\mathrm{X}$ \\
\hline 5 - Physical hedges & $\mathrm{X}$ & $\mathrm{X}$ \\
\hline $\begin{array}{l}\text { 6- Physical hedges with elec- } \\
\text { tricity futures }\end{array}$ & $\mathrm{X}$ & $\mathrm{X}$ & $\mathrm{X}$ \\
\hline $\begin{array}{l}7 \text { - Physical hedges with gas } \\
\text { futures }\end{array}$ & & & \\
\hline $\begin{array}{l}\text { 8- Physical hedges with both } \\
\text { electricity and gas futures }\end{array}$ & & & \\
\hline
\end{tabular}

Other parameters, including electricity and heat loads, the $\mathrm{CO}_{2}$ tax, and the risk-free interest rate, are specified in Table 4. Note that the tax on $\mathrm{CO}_{2}$ emissions and operational and maintenance costs remain constant in real terms over the entire time horizon. Using four main periods with two sources of uncertainty results in 64 nodes, which produces 640 scenarios in total assuming 10 subscenarios per node. For each case, we examine different regimes in terms of the level of risk aversion $(B)$. With these numerical examples, we examine whether on-site generation investments can be regarded as physical hedges to mitigate the consumer's risk exposure and explore how they interact with financial hedges, such as electricity and gas futures. The optimisation problems are implemented as mixed-integer linear programs (MILPs) in the General Algebraic Modeling System (GAMS) using the basic open-source nonlinear mixed integer programming (BONMIN, see https://projects.coin-or.org/Bonmin) solver on a desktop with an Intel Core i7 $2.79 \mathrm{GHz}$ CPU and 8 GB RAM. The solution times range from 50 to 400 minutes.

\subsection{Discussion}

Our findings confirm that on-site generation with CHP reduces both expected energy costs and $\mathrm{CO}_{2}$ emissions compared to cases with no on-site investment. In addition, the results 
Table 2: Available microturbine (MT) technologies with and without CHP

\begin{tabular}{|c|l|l|l|l|c|}
\hline $\begin{array}{l}\text { Technology } \\
\text { index, } i\end{array}$ & $\begin{array}{l}\text { Type of genera- } \\
\text { tion unit }\end{array}$ & $\begin{array}{l}\text { Capacity, } \\
K_{i}^{\mathrm{e}} \\
\left(\mathrm{kW}_{\mathrm{e}}\right)\end{array}$ & $\begin{array}{l}\text { Electrical } \\
\text { con- } \\
\text { version } \\
\text { efficiency, } \\
E_{i}^{\mathrm{e}}\end{array}$ & $\begin{array}{l}\text { Total efficiency of } \\
\text { producing elec- } \\
\text { tricity and useful } \\
\text { thermal energy, } \\
E_{i}^{\mathrm{e}}+E_{i}^{\mathrm{e}} E_{i}^{\mathrm{h}}\end{array}$ & $\begin{array}{l}\text { Total invest- } \\
\text { ment cost } \\
(\mathrm{M} €)\end{array}$ \\
\hline 1 & MT-small-1 & 200 & $30 \%$ & $30 \%$ & 0.20 \\
\hline 2 & MT-small-2 & 400 & $30 \%$ & $30 \%$ & 0.40 \\
\hline 3 & MT-medium & 600 & $30 \%$ & $30 \%$ & 0.60 \\
\hline 4 & $\begin{array}{l}\text { MT-CHP-small- } \\
1\end{array}$ & 200 & $27 \%$ & $78 \%$ & 0.27 \\
\hline 5 & $\begin{array}{l}\text { MT-CHP-small- } \\
2\end{array}$ & 400 & $27 \%$ & $78 \%$ & 0.54 \\
\hline 6 & $\begin{array}{l}\text { MT-CHP- } \\
\text { medium }\end{array}$ & 600 & $35 \%$ & $88 \%$ & 0.77 \\
\hline
\end{tabular}

Table 3: Process parameters for electricity and gas prices

\begin{tabular}{|c|c|c|}
\hline & Electricity & Gas \\
\hline Starting price $(€ / M W h)$ & 49.0 & 21.0 \\
\hline Yearly average spot price: & & \\
\hline Price volatility $\left(\sigma_{o}^{\mathrm{e}}, \sigma_{0}^{\mathrm{g}}\right)$ & $27.5 \%$ & $22.5 \%$ \\
\hline Price correlation $\left(\rho_{\mathrm{o}}\right)$ & 0.80 & \\
\hline $\begin{array}{l}\text { Quarter-yearly average spot price: } \\
\text { Price volatility }\left(\sigma_{\mathrm{q}}^{\mathrm{e}}, \sigma_{\mathrm{q}}^{\mathrm{g}}\right) \\
\text { Price correlation }\left(\rho_{\mathrm{q}}\right)\end{array}$ & $\begin{array}{r}30.1 \% \\
0.83\end{array}$ & $18.9 \%$ \\
\hline $\begin{array}{l}\text { Two-yearly futures: } \\
\text { Risk premium }\left(R^{\mathrm{e}}, R^{g}\right)\end{array}$ & $13 \%$ & $3 \%$ \\
\hline
\end{tabular}

indicate that on-site generation can hedge against volatile electricity prices, even if on-site generation has low efficiency or if the spread between electricity and gas prices decreases. Finally, we show that on-site generation as a physical hedge can be substituted with or complemented by financial hedges. The main results for a risk-neutral consumer $(B=0)$ based on cases in Table 1 are summarised in Table 5. Table 6 presents the same results for a maximally risk-averse $(B=\infty)$ consumer. Note that, due to no-arbitrage futures pricing, futures purchases are always zero in the risk-neutral regime. By comparing the expected cost and the CVaR for any case, it is possible to appreciate the dispersal of optimal solutions. For example, focusing on Case 8-w/o CHP, the expected cost can go from being $€ 7.59 \mathrm{M}$ 
Table 4: Demand parameters and $\mathrm{CO}_{2}$ tax

\begin{tabular}{|l|l|}
\hline Length of subperiod $(H)$ & $0.25 \mathrm{a}$ \\
Length of main period $(G)$ & $2 \mathrm{a}$ \\
Electricity demand $\left(D^{\mathrm{e}}\right)$ & $1 \mathrm{MW}$ \\
Heat demand $\left(D^{\mathrm{h}}\right)$ & $1.5 \mathrm{MW}$ \\
$\mathrm{CO}_{2}$ emissions tax $\left(L^{\mathrm{c}}\right)$ & $€ 21 /$ ton \\
Operational and maintenance cost $\left(V^{\mathrm{e}}\right)$ & $€ 2 / \mathrm{MWh}$ \\
Risk-free annual interest rate $(R)$ & $1 \%$ \\
\hline
\end{tabular}

on average to $€ 12.83 \mathrm{M}$ in the $5 \%$ worst-case outcome if the consumer is risk neutral (Table 5). By contrast, this spread is narrowed down when the consumer is maximally risk averse (Table 6): the expected cost ranges only from $€ 8.10 \mathrm{M}$ on average to $€ 11.82 \mathrm{M}$ in the $5 \%$ worst-case outcome.

Table 5: Results in a risk-neutral regime $(B=0)$

\begin{tabular}{|l|c|c|c|c|c|}
\hline Case & $\begin{array}{c}\text { Expected } \\
\text { cost } \\
(\mathrm{M} €)\end{array}$ & $\begin{array}{c}\mathrm{CVaR} \\
(\mathrm{M} €)\end{array}$ & $\begin{array}{c}\text { Installed } \\
\text { capacity } \\
\left(\mathrm{kW}_{\mathrm{e}}\right)\end{array}$ & $\begin{array}{c}\text { Expected } \\
\mathrm{CO}_{2} \\
\text { emissions } \\
\text { (kiloton) }\end{array}$ & $\begin{array}{c}\text { Overall } \\
\text { energy } \\
\text { efficiency }\end{array}$ \\
\hline $\begin{array}{l}\text { Cases 1-4 and } \\
\text { Cases 5-8 w/o } \\
\text { CHP }\end{array}$ & 7.59 & 12.83 & 0 & 59.19 & $72.2 \%$ \\
\hline Cases 5-8 w/ CHP & 7.02 & 10.69 & 800 & 49.14 & $79.0 \%$ \\
\hline
\end{tabular}

Insight 1: CHP reduces the expected cost compared to purchasing electricity from the market or generating electricity without heat recovery.

From Table 5, the installation of CHP in Cases 5-8-w/ CHP leads to a significant decrease in expected cost compared to Cases 1-4 and Cases 5-8-w/o CHP. Over the eight-year period, the expected cost with CHP is reduced by $4.5 \%$. Furthermore, compared to Cases 1-4, the overall efficiency of the consumer increases in Cases 5-8-w/ CHP. Note that the benchmark for efficiency is relatively high as a significant proportion of Germany's electricity is generated using nuclear power (although current policy favours its phase-out by the year 2022) and renewable energy sources. Nevertheless, this modest efficiency increase in Cases 5-8-w/ CHP translates into a significant decrease in $\mathrm{CO}_{2}$ emissions over the eight-year period. It 
Table 6: Results in a risk-averse regime $(B=\infty)$

\begin{tabular}{|l|c|c|c|c|c|c|c|c|}
\hline Case & $\begin{array}{c}\text { Expected } \\
\text { cost } \\
(\mathrm{M} €)\end{array}$ & $\begin{array}{c}\mathrm{CVaR} \\
(\mathrm{M} €)\end{array}$ & $\begin{array}{c}\text { Installed } \\
\text { capacity }\end{array}$ & $\begin{array}{c}\text { Electricity } \\
\text { futures }^{\mathrm{a}}\end{array}$ & $\begin{array}{c}\text { Gas } \\
\text { futures } \\
\text { for } \\
\text { boiler }^{\mathrm{b}}\end{array}$ & $\begin{array}{c}\text { Gas } \\
\text { futures } \\
\text { for MTc }\end{array}$ & $\begin{array}{c}\text { Expected } \\
\mathrm{CO}_{2} \\
\text { emissions } \\
\text { (kiloton) }\end{array}$ & $\begin{array}{c}\text { Overall } \\
\text { energy } \\
\text { efficiency }\end{array}$ \\
\hline 1 & 7.59 & 12.83 & 0 & $0 \%$ & $0 \%$ & $0 \%$ & 59.19 & $72.2 \%$ \\
\hline 2 & 7.70 & 12.02 & 0 & $9.0 \%$ & $0 \%$ & $0 \%$ & 59.19 & $72.2 \%$ \\
\hline 3 & 7.62 & 12.63 & 0 & $0 \%$ & $10.7 \%$ & $0 \%$ & 59.19 & $72.2 \%$ \\
\hline 4 & 7.69 & 11.97 & 0 & $7.0 \%$ & $3.8 \%$ & $0 \%$ & 59.19 & $72.2 \%$ \\
\hline 5 -w/ CHP & 7.02 & 10.69 & 800 & $0 \%$ & $0 \%$ & $0 \%$ & 49.14 & $79.0 \%$ \\
\hline 6-w/ CHP & 7.03 & 10.63 & 800 & $1.1 \%$ & $0 \%$ & $0 \%$ & 49.14 & $79.0 \%$ \\
\hline 7-w/ CHP & 7.06 & 10.48 & 800 & $0 \%$ & $1.7 \%$ & $3.0 \%$ & 48.96 & $79.2 \%$ \\
\hline 8-w/ CHP & 7.07 & 10.44 & 800 & $0.7 \%$ & $1.6 \%$ & $3.1 \%$ & 48.96 & $79.2 \%$ \\
\hline 5-w/o CHP & 7.88 & 12.30 & 800 & $0 \%$ & $0 \%$ & $0 \%$ & 60.86 & $68.1 \%$ \\
\hline 6-w/o CHP & 7.80 & 11.96 & 400 & $6.7 \%$ & $0 \%$ & $0 \%$ & 60.02 & $70.0 \%$ \\
\hline 7-w/o CHP & 7.91 & 12.06 & 800 & $0 \%$ & $8.2 \%$ & $0.4 \%$ & 60.87 & $68.0 \%$ \\
\hline 8-w/o CHP & 8.10 & 11.82 & 600 & $5.6 \%$ & $9.2 \%$ & $0.7 \%$ & 61.20 & $68.3 \%$ \\
\hline
\end{tabular}

${ }^{a}$ Fraction of electricity consumption supplied by electricity futures

b Fraction of heat consumption from boiler supplied by gas futures

c Fraction of electricity consumption supplied by gas futures

is equivalent to a $2.3 \%$ annual rate of decline over the same period, which is significantly larger than the $0.5 \%$ annual decrease recorded over the last eight-year period in Germany. This result provides support for German CHP laws, which aim to promote CHP installation in order to reach the 2020 targets.

\section{Insight 2: On-site generation reduces the consumer's risk exposure compared to} purchasing electricity from the spot market.

The CVaR of the consumer can be diminished by decreasing either its expected cost or the volatility of its running cost. In fact, the consumer's CVaR is the highest when it meets all of its electricity demand by purchasing electricity from the spot market and uses the boiler for heating by purchasing all of its gas from the spot market. When CHP is installed in Case 5-w/ CHP, both under risk-neutral and risk-averse regimes (see Tables 5 and 6), the consumer's CVaR decreases by $16.7 \%$ compared to Case 1 . As the expected cost in Case 5-w/ CHP reduces by $4.5 \%$ relative to Case 1, the remaining part of the CVaR reduction, 
$12.2 \%$, is due only to the lower volatility of the cost of running the energy system. Thus, the majority of the reduction in the CVaR derives from swapping electricity spot purchases for gas spot purchases using CHP. This risk-reducing effect of CHP persists even when gas prices increase enough to turn the spark spread, i.e., the difference between the electricity price and the cost of generation from gas, negative. In effect, CHP serves as a physical hedge that enables a risk-averse consumer to swap electricity for gas under certain scenarios. The CVaR is reduced the same way in Cases 5-8-w/o CHP, but the consumer invests in on-site generation only under risk-averse regimes. Since the MT w/o CHP has low efficiency, it cannot reduce the expected cost relative to Case 1 (see Table 6); however, it can still reduce the consumer's CVaR by using gas spot with low volatility when the electricity price peaks.

\section{Insight 3: Electricity futures and on-site generation are substitutes.}

As consumers also have the possibility to hedge against price risk through financial markets, it is important to assess how the availability of electricity futures affects the consumer's investment decisions in on-site generation. Comparing the cases with risk-averse regimes (Case 2 and Case 6-w/ CHP in Table 6), the proportion of electricity futures purchased decreases significantly when CHP is present. Since CHP generation is very efficient, it can decrease CVaR at a lower cost by producing energy on-site whenever the spot electricity price peaks. Electricity futures have less scope for CVaR reduction and are, therefore, used very rarely. Moreover, when only the less efficient MT w/o CHP can be installed, the availability of electricity futures decreases the need for on-site generation. This is why the installed capacity drops to $400 \mathrm{~kW}_{\mathrm{e}}$ in Case 6-w/o CHP compared to $800 \mathrm{~kW}_{\mathrm{e}}$ in Case 5w/o CHP. These findings show that electricity futures and on-site generation are substitutes.

\section{Insight 4: Gas futures and on-site generation are complements.}

The consumer can purchase gas futures for either on-site generation or for boiler heat production. Since the gas spot price has low volatility, gas futures for the boiler can reduce 
the CVaR only slightly. Nevertheless, as the boiler is more efficient than the MT w/o CHP, these purchases assist on-site investment in Case 8-w/o CHP, where the installed capacity is $200 \mathrm{~kW}_{\mathrm{e}}$ higher compared to Case 6-w/o CHP when only electricity futures are available (see Table 6). Gas futures for on-site generation would increase the running cost for the consumer in Case 8-w/o CHP; however, the consumer can mitigate some of the price volatility of spot gas for the MT by purchasing gas futures for the more efficient boiler. On the other hand, when CHP is installed, the consumer purchases most of the gas futures for the MT, thereby further reducing the consumer's exposure to electricity price volatility. Therefore, while the combined share of gas futures purchases for the MT and for the boiler are the lowest in the cases w/ CHP, gas futures become more cost-effective at reducing CVaR when CHP is present.

According to [33], the biggest obstacles to CHP adoption in Germany are risk aversion and an unfavourable gas spark spread. This is why it is important to note that, in fact, on-site generation can work as a physical hedge by reducing the consumers' CVaR, which is not captured by NPV and real options analyses. In fact, our results demonstrate that under a positive gas spark spread, even cheaper but less-efficient technologies, i.e., microturbines without heat exchangers, can limit risk exposure to peaking electricity prices. Furthermore, consumers can decrease their expected cost by investing in CHP, which can also function as an efficient hedge in case of a significant reduction in the average gas spark spread. However, a liquid electricity futures market might have an adverse effect on on-site generation. The availability of electricity futures can decrease the willingness of risk-averse consumers to invest in technologies w/o CHP since they can be as effective at reducing CVaR as on-site generation without heat recovery. On the other hand, the availability of gas futures can contribute to more investment in on-site generation as shown in Cases 7-w/ and w/o CHP. While financial hedges play an important role in risk management, from a social point of view, CHP investments provide more benefits in terms of lower $\mathrm{CO}_{2}$ emissions and more reliable electricity supply. Thus, policies affecting electricity and gas markets can also influence 
progress towards enhancing energy sustainability. To examine how the interaction between physical and financial hedges affect on-site generation investment, we next investigate each type of hedge separately.

\subsection{Limitations of Financial Hedging Alone}

In order to understand better the interaction between financial and physical hedges, we first examine the effectiveness of financial hedging alone. To do so, we focus on the efficient frontiers for Cases 1-4. Such frontiers are delimited by varying the $B$ parameter in order to make determinations about the mean-risk tradeoff. The rate of tradeoff can be analysed by comparing the slope of the mean-risk efficient frontier, from which we can derive the amount of $\mathrm{CVaR}$ reduction per $€ 1$ increase in the expected cost (see Fig. 33). There are four efficient frontiers here, but the one for Case 1 is just a single point as the consumer has no scope to adjust its energy procurement when neither financial nor physical hedges are available. Furthermore, the efficient frontiers for Cases $2-4$ share the risk-neutral point at $B=0$ with each other and Case 1. Thus, the dotted lines emphasise the shared initial point among the four efficient frontiers.

The largest decrease in CVaR occurs between $B=0$ and $B=0.35$. At this level of risk aversion, gas futures are more efficient than electricity futures at reducing $\mathrm{CVaR}$, i.e., a $€ 1$

increase in expected cost with gas futures leads to larger CVaR reduction, but the effect of electricity futures is larger, i.e., they reduce the CVaR by $6.3 \%$ compared to $1.6 \%$ with gas futures. This is because the electricity spot price is more volatile than the gas spot price, which means that electricity futures can reduce CVaR to a larger extent, even though their risk premium is higher (Table 3). Consequently, a consumer with only financial hedges can reduce its CVaR by purchasing mostly electricity futures as both financial hedges would result in a total CVaR reduction of $6.7 \%$. 


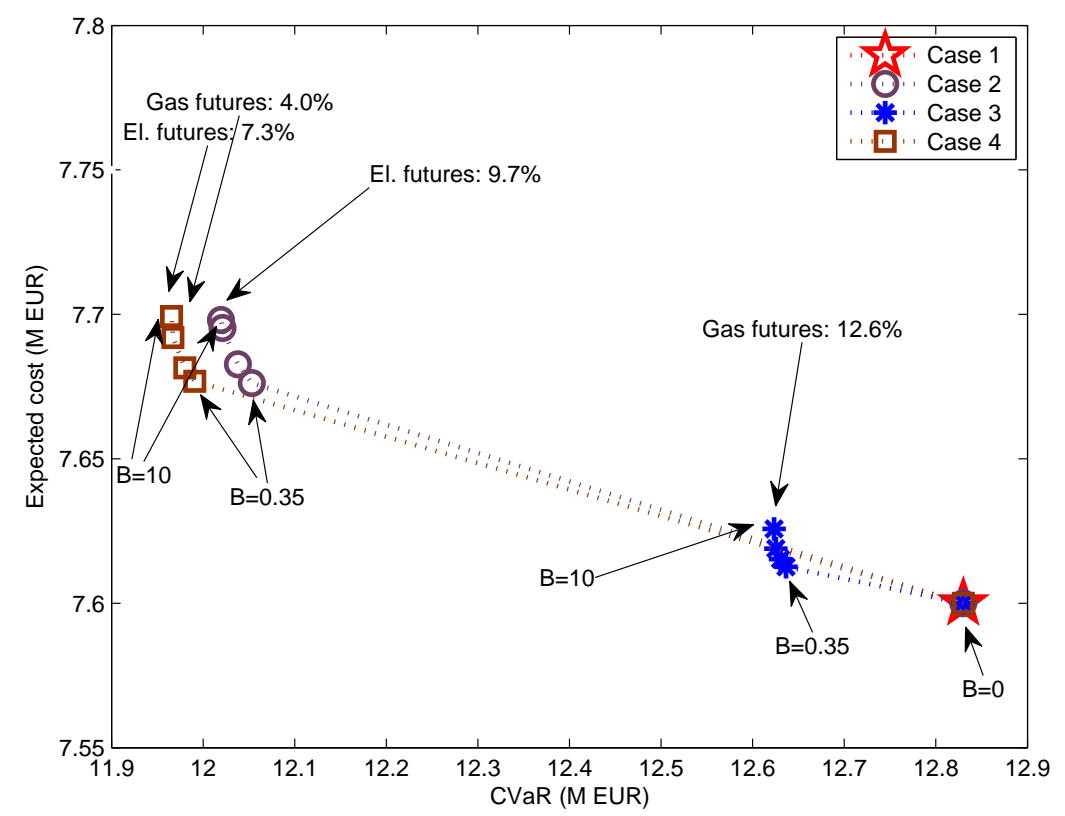

Figure 3: Efficient frontiers for Cases 1-4, i.e., no physical hedges

\subsection{Impact of Financial Hedging on MT without Heat Recovery}

We next examine the impact of financial hedges when an MT w/o CHP is installed. As a starting point, compared to the purely financial hedges in Cases 2-4, a solely physical hedge, i.e., an MT w/o CHP on its own, is less effective: the maximum CVaR reduction in Case $5-\mathrm{w} / \mathrm{o}$ CHP is $4.1 \%$, compared to $6.7 \%$ with financial hedges, and is reached at a much higher cost. The reason for this is that the MT w/o CHP has a low electrical conversion rate, which can be used only in a few scenarios, but its capital cost increases the consumer's expenditure in each scenario. Furthermore, the consumer can decide in every main period whether to enter into futures contracts, which makes financial hedges less burdensome on the expected cost. Nevertheless, installing an MT w/o CHP on its own is still attractive for a risk-averse consumer. Plus, it becomes more effective when coupled with financial hedges.

Insight 2-w/o CHP: Less efficient on-site generation can also reduce the consumer's risk exposure. 

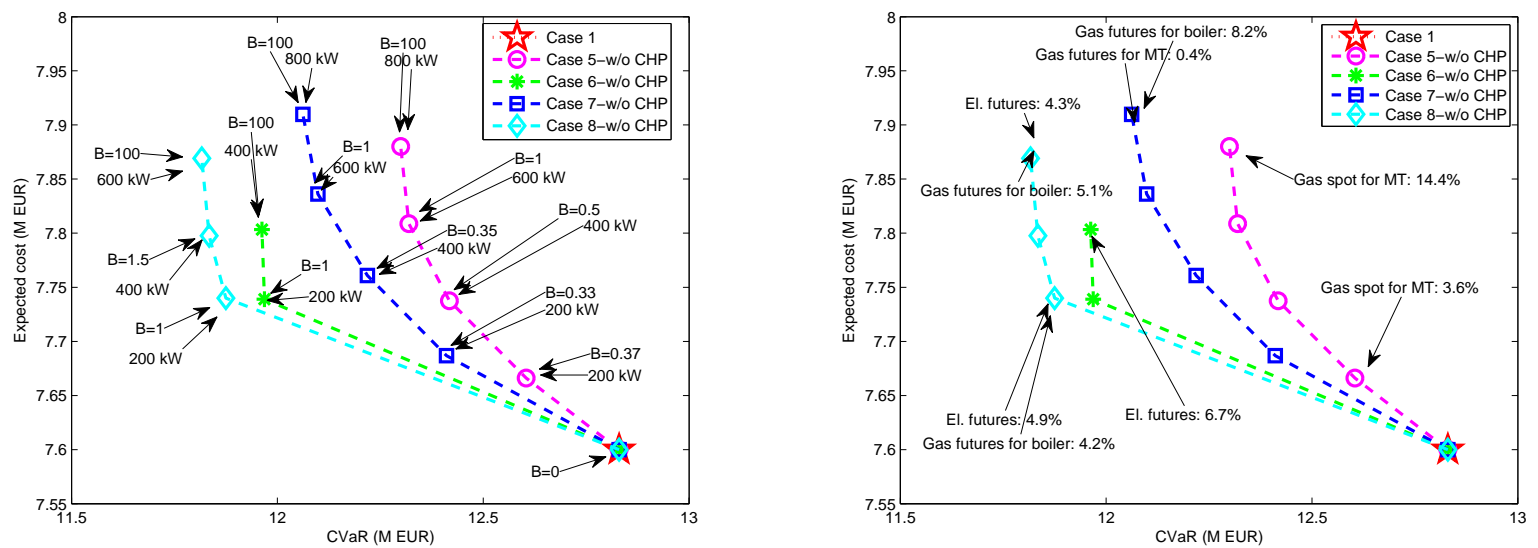

Figure 4: Efficient frontiers for Cases 5-8 w/o CHP with installed capacities (left panel) and energy purchases (right panel) indicating the impact of physical hedges

From Tables 5 and 6 , we conclude that an MT w/o CHP is always inferior to CHP, but it still can function as a physical hedge. In the risk-neutral regime $(B=0)$, the consumer does not install any on-site generation in cases w/o CHP. Nevertheless, in risk-averse regimes $(B>0)$, the consumer installs microturbines whenever they are available. Furthermore, the more risk averse the consumer becomes, the more generation capacity it installs even without the availability of financial hedges (left panel of Fig. 4). As above, the reason for this is that the volatility of the gas spot price is lower than that of the electricity spot price. The consumer can, therefore, decrease its CVaR by installing on-site generation and swapping the volatile electricity spot price for the less volatile gas spot price. For example, in Case 5 -w/o CHP at $B=0.37$, the consumer invests in $200 \mathrm{~kW}_{\mathrm{e}}$ of on-site generation (left panel of Fig. 4). Due to its low efficiency, the microturbine supplies only $3.6 \%$ of the electricity load (right panel of Fig. (4) but has the potential to supply 20\%. Thus, even though the microturbine lies mostly idle, it still enables the consumer to avoid peaking electricity prices, thereby significantly decreasing its CVaR.

\section{Insight 3-w/o CHP: The degree of the substitution effect between electricity futures and on-site generation is determined by the level of risk aversion.}


Fig. 4 shows that the consumer invests in less on-site generation capacity when electricity futures are available. This indicates that electricity futures and on-site generation are substitutes in the sense that increasing the purchases of electricity futures reduces the scope of on-site generation for CVaR reduction. Conversely, lowering the risk premium for electricity futures (decreasing the investment cost of MT) reduces the risk-averse investment in on-site generation (electricity futures). However, this substitution effect varies with the cross-price elasticity depending on the level of risk aversion. At $B=100$, a one percentage point decrease in the risk premium for electricity futures leads to lower on-site generation investment. On the other hand, at the same level of risk aversion, only a $20 \%$ decrease in the investment cost would result in more on-site generation investment and less futures purchases. At a lower level of risk aversion, $B=1$, when the consumer installs the $200 \mathrm{~kW}_{\mathrm{e}} \mathrm{MT}$, a $14 \%$ decrease in the price of MT is sufficient to increase the demand for on-site generation to 400 $\mathrm{kW}_{\mathrm{e}}$, while only a 12 percentage point decrease in the risk premium would result in no onsite investment and increased electricity futures purchases. The substitution effect between electricity futures and on-site generation varies because their effects on CVaR reduction also vary. Investing in on-site generation gives the option to the consumer to swap gas spot prices for electricity prices. Consequently, on-site generation with low efficiency requires a sufficiently large spread between gas and electricity spot prices such that the CVaR reduction from on-site generation remains larger than the increase in the expected cost. As such a price spread occurs infrequently, the $400 \mathrm{~kW}_{\mathrm{e}}$ MT remains idle predominantly while the $200 \mathrm{~kW}_{\mathrm{e}} \mathrm{MT}$ is sufficient most of the time. This is why the substitution effect of electricity futures is larger when the $400 \mathrm{~kW}_{\mathrm{e}} \mathrm{MT}$ is installed. Thus, in terms of CVaR reduction, MT $\mathrm{w} / \mathrm{o}$ CHP is more competitive against financial hedges if installed in a small capacity.

Insight 4-w/o CHP: The complementarity between gas futures and on-site investment depends on the level of risk aversion.

At $B=100$ in Case 8-w/o CHP, a two percentage point decrease in the risk premium for gas 
futures increases investment in on-site generation from $600 \mathrm{~kW}_{\mathrm{e}}$ to $800 \mathrm{~kW}$. At the same level of risk aversion, a $10 \%$ decrease in the investment cost increases the on-site investment to $800 \mathrm{~kW}_{\mathrm{e}}$ and, thus, increases the demand for gas futures for boiler heat production from $5.1 \%$ to $6.9 \%$ of the heat demand. As a result, gas futures have a larger impact when the marginal CVaR reduction of on-site investment is small. In Case 8-w/o CHP, this is also due to the presence of electricity futures, which are substitutes for on-site generation. At the risk-aversion levels specified in the left panel of Fig. 4, a decrease in the risk premium for gas futures does not lead to more investment. On the other hand, a decrease in the investment cost leads to more investment, which in turn leads to more gas futures purchases. Therefore, in Case 7-w/o CHP, on-site generation is a better complement as it has a stronger effect on gas futures purchases than gas futures purchases have on the investment decision. Nevertheless, the presence of gas futures still affects the investment decision, as indicated by the mean-risk efficient frontiers of Cases 5 and 7-w/o CHP. When gas futures are present in Case 7-w/o CHP, investment decisions are triggered at a lower value of $B$ compared to Case 5. For example, the consumer invests in $400 \mathrm{~kW}_{\mathrm{e}}$ at $B=0.35$ when gas futures are available and at $B=0.50$ when gas futures cannot be purchased.

\subsection{Impact of Financial Hedging on CHP}

Having demonstrated the efficacy of CHP in decreasing the consumer's expected cost in Section 4.2, we now further examine Cases 5-8-w/ CHP by focusing on the CHP's role in risk management. Relative to Case 1, Cases 5-8-w/ CHP have much lower expected cost and CVaR, e.g., compare Figs. 3] and 5, Furthermore, the installed generation capacity is the same in all risk-neutral and risk-averse regimes, i.e., $800 \mathrm{~kW}_{\mathrm{e}}$. As the CHP is efficient,

the consumer uses on-site generation to decrease its expected cost in the risk-neutral regime whenever the electricity price peaks. Thus, there is no scope for further CVaR reduction by swapping electricity for gas, and, hence, the consumer does not install more capacity in 
risk-averse regimes.

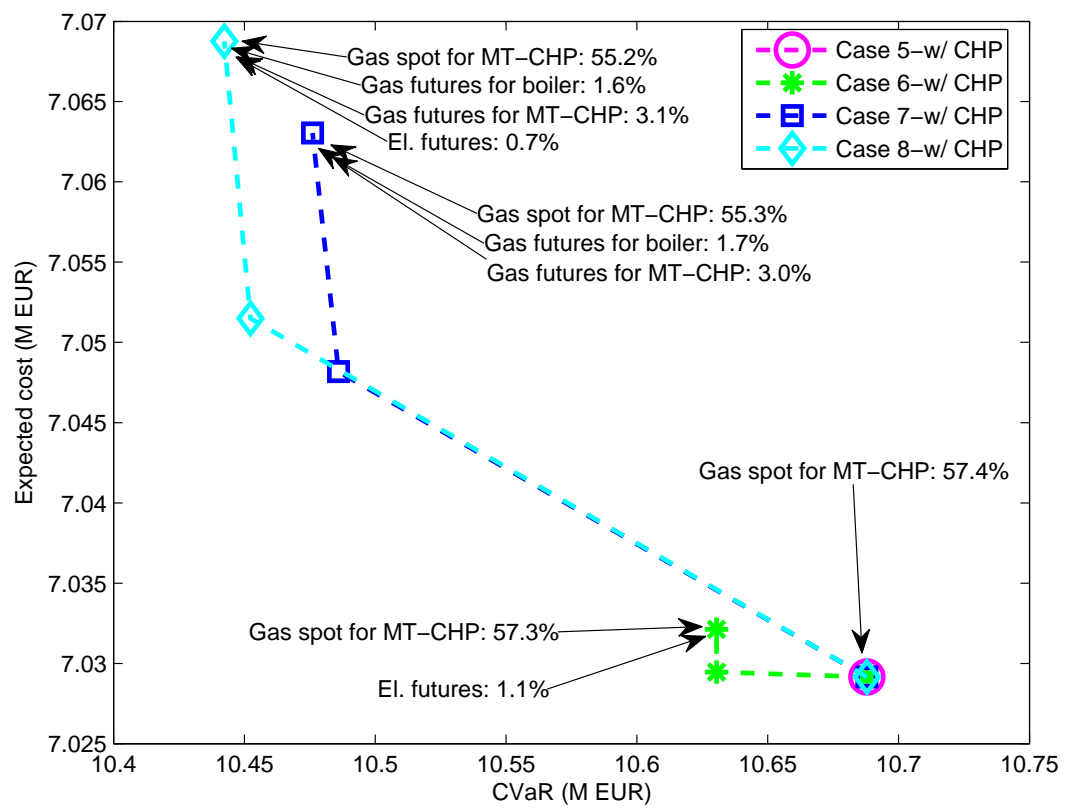

Figure 5: Efficient frontiers and energy purchases for Cases 5-8 w/ CHP under $B=0$, $B=1$, and $B=100$ indicating the impact of physical hedges

Insight 3-w/ CHP: The substitution effect of electricity futures for on-site generation is much weaker with CHP in comparison with MT w/o CHP.

While the shares of both electricity and gas futures are lower compared to Cases 5-8-w/o $\mathrm{CHP}$, the decrease in the use of electricity futures is more than that of gas futures (see Case 8-w/ CHP in Fig. 5 and Case 8-w/o CHP in the right panel of Fig. 4). When the installed generation capacity cannot be used economically, the electricity spot price is low with low volatility; therefore, the consumer purchases electricity futures at only those main scenario nodes when the average gas spot price is relatively high and the electricity spot price is still volatile. As this happens rarely, the share of electricity futures is much lower than in the cases w/o CHP. This indicates that MT w/ CHP and electricity futures are substitutes. Since the consumer invests in CHP in the risk-neutral regime, the substitution effect between on-site generation and electricity futures is much smaller for the risk-averse consumer. In Case 6-w/ 
CHP at $B=100$, only a 9 percentage point decrease in the risk premium for electricity futures leads to $200 \mathrm{~kW}_{\mathrm{e}}$ less on-site investment. In the same case, the investment cost of MTs w/ CHP needs to increase by $40 \%$ to trigger additional electricity futures purchases. As the share of electricity purchases is low, increased risk premiums for electricity futures cannot affect the investment decision. Thus, investment in CHP is relatively insensitive to large changes in the electricity futures market.

\section{Insight 4-w/ CHP: Gas futures for the boiler are substitutes, while gas futures for MT are complements for CHP investment.}

The effect of gas futures on the use of on-site generation is somewhat ambiguous. On the one hand, the use of on-site generation increases the value of gas futures for MT; thus, gas futures and on-site generation are complements. On the other hand, gas futures might decrease the risk-averse demand for CHP as they can reduce the CVaR when used with the boiler. While in the cases w/o CHP the boiler is operated independently of the MT, in the cases w/ CHP, the consumer does not run the boiler and the CHP at full capacity at the same time as this would generate waste heat. This is why gas futures for boiler and on-site generation with $\mathrm{CHP}$ can be substitutes. In Case 7 -w/ $\mathrm{CHP}$ at $B=100$, a change in the risk premium for gas futures does not affect the investment decision. However, when the investment cost increases, the demand for gas futures for MT decreases, while the demand for gas futures for boiler increases. The same interaction can be observed when we run Case 8-w/ CHP but without gas futures for MT. In the most risk-averse regime, the consumer decreases its investment to $600 \mathrm{~kW}_{\mathrm{e}}$ and increases its electricity futures and gas futures for boiler purchases. Comparing the effects of electricity and gas futures, in Case 8-w/ CHP, a 9 percentage point decrease in the risk premium of electricity futures results in a $200 \mathrm{~kW}_{\mathrm{e}}$ decrease in on-site investment. However, if this is accompanied by a one percentage point decrease in the premium of gas futures, then the consumer maintains its $800 \mathrm{~kW}_{\mathrm{e}}$ investment. Thus, gas futures and on-site generation are complements as the substitution effect of gas 
futures for the boiler is dominated by the complementarity effect of gas futures for MT in most cases. The substitution effect of gas futures eclipses the complementarity effect only when the economics of CHP deteriorate significantly. For example, in Case 8-w/ CHP at $B=100$, if the cost of CHP increases by $40 \%$, then the consumer invests in less on-site generation; however, if gas futures for the boiler were not available, then it would still invest in $800 \mathrm{~kW}_{\mathrm{e}}$ CHP. Thus, the availability of gas futures results in more investment in CHP under the current market conditions.

These insights are robust with respect to the values of the uncertain parameters. For example, with higher electricity price volatility, the value of on-site generation as a physical hedge increases compared to financial hedges. With lower correlation between electricity and gas prices, on-site generation works less efficiently as a physical hedge, but the complementarity effect of gas futures increases.

\section{Conclusions}

Deregulation has introduced new challenges and opportunities within the energy sector. Consumers face uncertain electricity and gas prices, which significantly increases their risk exposure. On the other hand, consumers can now invest in on-site generation or use futures to hedge against increased price risk. While financial hedges play an increasingly important role in the energy markets, investment in new technologies provides more social benefits, such as higher energy efficiency and lower $\mathrm{CO}_{2}$ emissions, as shown in [9]. Still, despite the ongoing efforts of policymakers to support CHP implementation, the investment rate is lagging behind the desired targets [29, 35, 36].

Possible explanations for this are volatile gas spark spreads and risk aversion among smaller potential investors. Indeed, managing the risk from such ventures requires more sophisticated decision support. Using stochastic programming, we show that even financial hedges alone enable the CVaR of the consumer to be reduced by $6.7 \%$ relative to procuring all 
energy on the spot market. On-site generation functions as an even more effective (physical) physical hedge against electricity price volatility, which is likely to increase due to the rising share of intermittent generation. Since conventional decision-making frameworks do not take into account risk aversion, decision makers without access to stochastic programming techniques might overlook the significant value of CHP as a physical hedge. As CHP is more energy efficient than purchasing electricity from the grid and using a gas-fired boiler for heat production, it is also associated with lower $\mathrm{CO}_{2}$ emissions and can help to achieve the 2020 goals set by the EU, e.g., CHP with financial hedging reduces expected $\mathrm{CO}_{2}$ emissions by $17.3 \%$ vis-à-vis using only the spot market. Likewise, the consumer's risk can be further decreased by using CHP along with electricity and gas futures, e.g., CHP together with financial hedging reduces the consumer's CVaR by $18.6 \%$ relative to relying on the spot market only for meeting its energy needs.

While we demonstrate that electricity futures and on-site generation are substitutes, the availability of electricity futures impedes investments mostly in technologies without CHP. Microturbines with heat recovery are more efficient hedges as they can swap the high volatility of the electricity price for the low volatility of the spot gas price. Consequently, the consumer is not exposed to peaks in electricity prices when the use of financial futures would be a more costly alternative. Intriguingly, we show that gas futures and on-site generation can complement each other as a consumer is more likely to install additional generation capacity when gas futures are available. In fact, the availability of gas futures can neutralise the substitution effect of electricity futures, thereby contributing to higher investment. Nevertheless, the interaction between financial and physical hedges depends on both the level of risk aversion of the consumer and on the underlying electricity and gas price processes.

As with any analysis focusing on long-term decisions, our work is limited by the assumptions that enable us to keep the investment problem computationally tractable. Since quarterly average spot prices have lower volatility than hourly spot prices, using them under- 
estimates the CVaR-reducing impact of CHP. Furthermore, consumers can purchase weekly and monthly electricity futures for base load, peak load, and off-peak load periods as well as monthly gas futures, which increase the CVaR-reducing potential of financial hedging. In addition to examining long-term investment decisions, investors also need to take into account short-term operational decisions when considering risk management using financial and physical hedges. Indeed, in spite of the capability of CHP to serve as an effective hedge against market risk and to support policy objectives, its adoption is hampered by barriers such as static building energy management systems (BEMS) currently installed by most consumers. Since these static BEMS are built on proprietary software, they require greater sophistication to be adjusted in order to incorporate more dynamic operational strategies. Rocha et al. 38] discuss such barriers in the context of short-term building operations. For this reason, we plan to focus our future research efforts on the optimal operation of an on-site generation system in the short and medium terms.

\section{Acknowledgements}

Maurovich-Horvat is grateful for support from the UCL Centre in Financial Computing. The research leading to these results has received funding from the European Union Seventh Framework Programme under grant agreement no. 260041 for Collaborative Project "Energy

Efficiency and Risk Management in Public Buildings" (EnRiMa). The authors are grateful to the department editor and three anonymous referees for their helpful feedback. All remaining errors are the authors' own.

\section{References}

[1] J.C. Ciscar, A. Iglesias, L. Feyen, L. Szabó, D. Van Regemorter, B. Amelung, and A. Soria, "Physical and economic consequences of climate change in Europe," Proceedings of the National Academy of Sciences, vol. 108, no. 7, pp. 2678-2683, 2011. 
[2] European Union. European Commission, Communication from the European Commission, A Roadmap for moving to a competitive low carbon economy in 2050, $\operatorname{COM}(2011)$. Brussels: European Commission; 2011.

[3] European Union. European Commission, Communication from the European Commission, Europe-2020, COM(2010). Brussels: European Commission; 2010.

[4] B.K. Sovacool, "Energy policymaking in Denmark: Implications for global energy security and sustainability," Energy Policy, vol. 61, pp. 829-839, 2013.

[5] R.B. Wilson, "Architecture of power markets," Econometrica, vol. 70, no. 4, pp. 1299$1340,2002$.

[6] T. Jamasb and M.G. Pollitt, "Electricity market reform in the European Union: Review of progress towards liberalisation and integration," The Energy Journal, vol. 26, pp. $11-41,2005$.

[7] C.K. Woo, M. King, A. Tishler, and L.C.H. Chow, "Costs of electricity deregulation," Energy, vol. 31, no. 6, pp. 747-768, 2006.

[8] R. Madlener and C. Schmid, "Combined heat and power generation in liberalised markets and a carbon-constrained world," GAIA-Ecological Perspectives for Science and Society, vol. 12, no. 2, pp. 114-120, 2003.

[9] A.S. Siddiqui, C. Marnay, J.L. Edwards, R. Firestone, S. Ghosh, and M. Stadler, "Effects of carbon tax on microgrid combined heat and power adoption," Journal of Energy Engineering, vol. 131, no. 3, pp. 2-25, 2005.

[10] A.S. Siddiqui, C. Marnay, R. Firestone, and N. Zhou, "Distributed generation with heat recovery and storage," Journal of Energy Engineering, vol. 133, no. 3, pp. 181-210, 2007. 
[11] K. Siler-Evans, M. G. Morgan, and I.L. Azevedo, "Distributed cogeneration for commercial buildings: Can we make the economics work?" Energy Policy, vol. 42, pp. 580-590, 2012.

[12] S.-E. Fleten, K.M. Maribu, and I. Wangensteen, "Optimal investment strategies in decentralized renewable power generation under uncertainty," Energy, vol. 32, no. 5, pp. 803-815, 2007.

[13] K.M. Maribu and S.-E. Fleten, "Combined heat and power in commercial buildings: Investment and risk analysis," The Energy Journal, vol. 29, no. 2, pp. 123-150, 2008.

[14] M. Wickart and R. Madlener, "Optimal technology choice and investment timing: a stochastic model of industrial cogeneration vs. heat-only production," Energy Economics, vol. 29, no. 4, pp. 934-952, 2007.

[15] A.S. Siddiqui and K. Maribu, "Investment and upgrade in distributed generation under uncertainty," Energy Economics, vol. 31, no. 1, pp. 25-37, 2009.

[16] M. Chronopoulos, B. De Reyck, and A.S. Siddiqui, "The value of capacity sizing under risk aversion and operational flexibility," IEEE Transactions on Engineering Management, vol. 60, no. 2, pp. 272-288, 2013.

[17] P. Kall and S.W. Wallace, Stochastic Programming. Wiley, 1994.

[18] J.R. Birge and F. Louveaux, Introduction to Stochastic Programming. Springer, 1997.

[19] A. Käki, A. Salo, and S. Talluri, "Scenario-based modeling of interdependent demand and supply uncertainties," IEEE Transactions on Engineering Management, vol. 61, no. 1, pp. 101-113, 2014.

[20] S.-E. Fleten and T.K. Kristoffersen, "Stochastic programming for optimizing bidding strategies of a Nordic hydropower producer," European Journal of Operational Research, vol. 181, no. 2, pp. 916-928, 2007. 
[21] M. Carrión, A.B. Philpott, A.J. Conejo, and J.M. Arroyo, "A stochastic programming approach to electric energy procurement for large consumers," IEEE Transactions on Power Systems, vol. 22, no. 2, pp. 744-754, 2007.

[22] J. Kettunen, D.W. Bunn, and W. Blyth, "Investment propensities under carbon policy uncertainty," The Energy Journal, vol. 32, no. 1, pp. 77-117, 2011.

[23] A.J. Conejo, M. Carrión, and J.M. Morales, Decision Making Under Uncertainty in Electricity Markets. Springer, 2010.

[24] H.X. Zhao and F. Magoulès, "A review on the prediction of building energy consumption," Renewable and Sustainable Energy Reviews, vol. 16, no. 6, pp. 3586-3592, 2012.

[25] P. Rocha, M. Kaut, and A.S. Siddiqui, "Energy-efficient building retrofits: An assessment of regulatory proposals under uncertainty," Energy, vol. 101, pp. 278-287, 2016.

[26] P. Artzner, F. Delbaen, J.-M. Eber, and D. Heath, "Coherent measures of risk," Mathematical Finance, vol. 9, no. 3, pp. 203-228, 1999.

[27] R.T. Rockafellar and S. Uryasev, "Conditional value-at-risk for general loss distributions," Journal of Banking \& Finance, vol. 26, no. 7, pp. 1443-1471, 2002.

[28] A. Golbach, Eine KWK-Roadmap für Deutschland. CODE2-Expertenworkshop, Berlin, 2013.

[29] Germany. Bundesministerium für Wirtschaft und Technologie, Kraft-WärmeKopplungs-Gesetz, 2012. Gesetz für die Erhaltung, die Modernisierung und den Ausbau der Kraft-Wärme-Kopplung. Berlin: Bundesministerium für Wirtschaft und Energie; 2012.

[30] L. Giaccone and A. Canova, "Economical comparison of CHP systems for industrial user with large steam demand," Applied Energy, vol. 86, no. 6, pp. 904-914, 2009. 
[31] L. Galanti and A.F. Massardo, "Micro gas turbine thermodynamic and economic analysis up to 500 kWe size," Applied Energy, vol. 88, no. 12, pp. 4795-4802, 2011.

[32] Hull, J.C., Options, Futures, and Other Derivatives. Chapter 13, pp. 290-291. Pearson, 2012.

[33] Belgium. The European Association for the Promotion of Cogeneration, European Cogeneration Review - Germany. Brussels: The European Association for the Promotion of Cogeneration, 2013.

[34] France. CDC Climate Research, Methodology - Tendances Carbone. Paris: Caisse des Dépôts, 2013.

[35] Germany. Bundesministerium für Wirtschaft und Arbeit, Kraft-Wärme-KopplungsGesetz. Gesetz für die Erhaltung, die Modernisierung und den Ausbau der Kraft-WärmeKopplung. Berlin: Bundesministerium für Wirtschaft und Energie, 2002.

[36] Germany. Bundesministerium für Wirtschaft und Technologie, Kraft-WärmeKopplungs-Gesetz. Gesetz für die Erhaltung, die Modernisierung und den Ausbau der Kraft-Wärme-Kopplung. Berlin: Bundesministerium für Wirtschaft und Energie, 2009.

[37] A. Gamba and L. Trigeorgis, "A log-transformed binomial lattice extension for multidimensional option problems," In 5th Annual International Conference on Real Options, Los Angeles, CA, 2001.

[38] P. Rocha, A.S. Siddiqui, and M. Stadler, "Improving energy efficiency via smart building energy management systems: A comparison with policy measures," Energy and Buildings, vol. 88, pp. 203-213, 2015. 


\section{Appendix A Notation}

\section{Sets}

$b(n) \in \mathcal{N} \backslash \mathcal{N}_{T}$ : ancestor node of node $n \in \mathcal{N} \backslash \mathcal{N}_{1}$

$\mathcal{I}$ : set of technologies

$\mathcal{M}:=\{1, \ldots, M\}:$ set of subperiods

$\mathcal{N}$ : set of nodes in the scenario tree

$\mathcal{N}_{t} \in \mathcal{N}$ : set of nodes belonging to main period $t \in \mathcal{T}$

$\mathcal{S}$ : set of subscenario paths at a given node in the scenario tree

$\mathcal{T}:=\{1, \ldots, T\}:$ set of main time periods

$t(n) \in \mathcal{T}$ : main time period of node $n \in \mathcal{N}$

\section{Fixed Parameters}

A: confidence level for the CVaR

$B$ : weight assigned to $\mathrm{CVaR}$

$C$ : $\mathrm{CO}_{2}$ emissions rate of the consumer from burning gas on-site (ton of $\mathrm{CO}_{2} / \mathrm{MWh}$ )

$D^{\mathrm{e}}$ : electricity load in each subperiod $\left(\mathrm{MW}_{\mathrm{e}}\right)$

$D^{\text {h }}$ : heat load in each subperiod (MW)

$E^{\text {b}}$ : boiler conversion efficiency, i.e., units of useful heat produced from one MWh of natural gas $(\mathrm{MWh} / \mathrm{MWh})$

$E_{i}^{\mathrm{e}}$ : electrical conversion efficiency, i.e., units of electricity produced from one MWh of natural gas, of technology $i \in \mathcal{I}\left(\mathrm{MWh}_{\mathrm{e}} / \mathrm{MWh}\right)$

$E_{i}^{\mathrm{h}}$ : heat capture rate from CHP, i.e., units of useful heat produced from one $\mathrm{MWh}_{\mathrm{e}}$ of electricity, of technology $i \in \mathcal{I}\left(\mathrm{MWh} / \mathrm{MWh}_{\mathrm{e}}\right)$

$G$ : length of each main period in years (a)

$H$ : length of each subperiod in years (a)

$J=8760$ : number of hours in a year $(\mathrm{h} / \mathrm{a})$ 
$K_{i}^{\mathrm{e}}$ : capacity of electricity generation unit of technology $i \in \mathcal{I}\left(\mathrm{MW}_{\mathrm{e}}\right)$

$K^{\text {b}}$ : capacity of boiler unit (MW)

$L^{\mathrm{c}}$ : tax on $\mathrm{CO}_{2}$ emissions $\left(€ /\right.$ ton of $\left.\mathrm{CO}_{2}\right)$

$N_{i}$ : amortised cost over $T \times M$ subperiods of installing technology $i \in \mathcal{I}$, paid per subperiod

$Q_{n}$ : probability of node $n \in \mathcal{N}$

$Q_{s}^{\text {s: }}$ conditional probability of subscenario path $s \in \mathcal{S}$ within a particular node

$R$ : risk-free interest rate per annum

$V^{\mathrm{e}}$ : variable operating and maintenance $(\mathrm{O} \& \mathrm{M})$ cost of electricity generation $(€ / \mathrm{MWh})$

\section{Random Parameters}

$F_{n}^{\mathrm{e}}$ : multi-subperiod-ahead forward price of electricity at node $n \in \mathcal{N}$ purchased at the beginning of the node's main period and delivered in each subperiod and subscenario path of the node $\left(€ / \mathrm{MWh}_{\mathrm{e}}\right)$

$F_{n}^{\mathrm{g}}$ : multi-subperiod-ahead forward price of natural gas at node $n \in \mathcal{N}$ purchased at the beginning of the node's main period and delivered in each subperiod and subscenario path of the node $(€ / \mathrm{MWh})$

$P_{n, s, m}^{\mathrm{e}}$ : spot price of electricity at node $n \in \mathcal{N}$ in subscenario path $s \in \mathcal{S}$ and subperiod $m \in \mathcal{M}\left(€ / \mathrm{MWh}_{\mathrm{e}}\right)$

$P_{n, s, m}^{\mathrm{g}}$ : spot price of gas at node $n \in \mathcal{N}$ in subscenario path $s \in \mathcal{S}$ and subperiod $m \in \mathcal{M}$ $(€ / \mathrm{MWh})$

\section{Decision Variables}

$\gamma_{n}$ : present value of the cumulative cost of satisfying the electricity and heat loads up until main period $t(n)$ at node $n \in \mathcal{N}(€)$

$\eta_{n}$ : auxiliary variable to calculate the CVaR at node $n \in \mathcal{N}(€)$

$\xi$ : value-at-risk at confidence level $A(€)$

$\varpi_{n}$ : the expected present value at beginning of main period $t(n)$ of the spot operational and 
amortised capital cost of all subperiods at node $n \in \mathcal{N}(€)$

$\Phi_{n}$ : total cost of purchasing futures for the consumer at node $n \in \mathcal{N}$ at the beginning of the node's main period $(€)$

$\Psi$ : total amortised capital cost for the selected technologies $(€)$

$\Omega_{n, s, m}$ : total spot operational cost of the consumer at node $n \in \mathcal{N}$ in subscenario path $s \in \mathcal{S}$ during subperiod $m \in \mathcal{M}(€)$

$h_{i, n, s, m}$ : recovered heat from technology $i \in \mathcal{I}$ used to meet heat load at node $n \in \mathcal{N}$ in subscenario path $s \in \mathcal{S}$ during subperiod $m \in \mathcal{M}(\mathrm{MWh})$

$w_{i}$ : binary variable, now-or-never decision to install technology $i \in \mathcal{I}$ at $t=1$

$x_{n, s, m}$ : electricity purchased from the spot market at node $n \in \mathcal{N}$ in subscenario path $s \in \mathcal{S}$ during subperiod $m \in \mathcal{M}\left(\mathrm{MWh}_{\mathrm{e}}\right)$

$x_{n}^{\mathrm{f}}$ : electricity futures purchased in node $n \in \mathcal{N}$ at the beginning of the node's main period, for delivery in all subscenario paths and in each subperiod of the node $\left(\mathrm{MWh}_{\mathrm{e}}\right)$

$y_{i, n, s, m}$ : natural gas purchased from the spot market for cogeneration using technology $i \in \mathcal{I}$ at node $n \in \mathcal{N}$ and in subscenario path $s \in \mathcal{S}$ during subperiod $m \in \mathcal{M}(\mathrm{MWh})$

$y_{i, n}^{\mathrm{f}}$ : natural gas futures purchased for cogeneration using technology $i \in \mathcal{I}$ in node $n \in \mathcal{N}$ at the beginning of the node's main period, for delivery in all subscenario paths and in each subperiod of the node (MWh)

$z_{n, s, m}$ : natural gas purchased from the spot market for boiler heat production at node $n \in \mathcal{N}$ in subscenario path $s \in \mathcal{S}$ during subperiod $m \in \mathcal{M}(\mathrm{MWh})$

$z_{n}^{\mathrm{f}}$ : natural gas futures purchased for boiler heat production in node $n \in \mathcal{N}$ at the beginning of the node's main period, for delivery in all subscenario paths and in each subperiod of the node (MWh)

\section{Appendix B Scenario Generation}

The electricity and gas price scenarios are generated in two steps. First, we use the scenario tree method to generate the average electricity $\left(\bar{P}_{n}^{\mathrm{e}}\right)$ and gas $\left(\bar{P}_{n}^{\mathrm{g}}\right)$ prices within each node 
$n \in \mathcal{N}$. At end of main period $t(n)$, the average electricity (gas) price can increase, $U_{n}^{\mathrm{e}}=+1$ $\left(U_{n}^{\mathrm{g}}=+1\right)$, or decrease $U_{n}^{\mathrm{e}}=-1\left(U_{n}^{\mathrm{g}}=-1\right)$. Thus, from each node there are four branches, each corresponding to a different state of the average electricity and gas prices (Fig. 6).

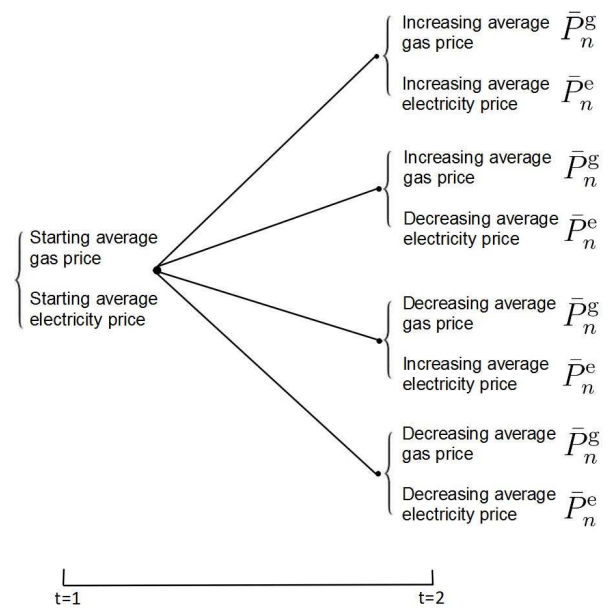

(a) Main scenarios

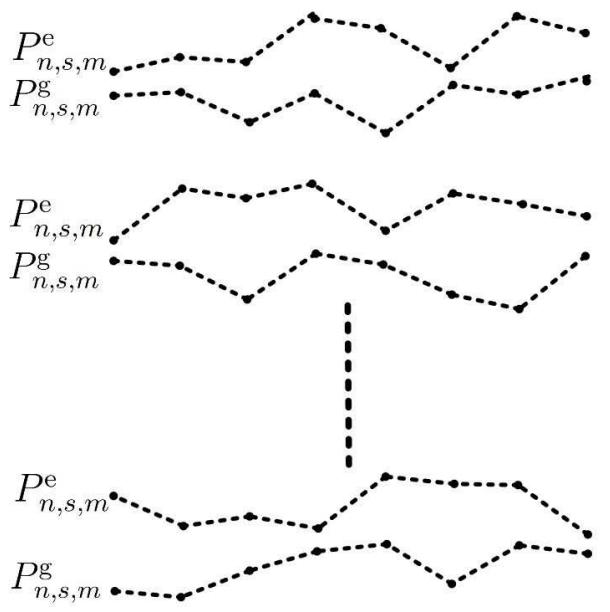

(b) Subscenarios

Figure 6: Scenario generation

We assume that the long-term average electricity and gas prices follow correlated geometric Brownian motions (GBMs) with zero drift, volatilities $\sigma_{\mathrm{o}}^{\mathrm{e}}$ and $\sigma_{\mathrm{o}}^{\mathrm{g}}$, respectively, and price correlation $\rho_{\mathrm{o}}$. The scenario tree is generated through an extension of the log-transformed binomial lattice [37].

$$
\begin{aligned}
& \ln \bar{P}_{n}^{\mathrm{e}}=\ln \bar{P}_{b(n)}^{\mathrm{e}}+\sigma_{\mathrm{o}}^{\mathrm{e}} \sqrt{G} U_{n}^{\mathrm{e}}, \quad \forall n \in \mathcal{N} \\
& \ln \bar{P}_{n}^{\mathrm{g}}=\ln \bar{P}_{b(n)}^{\mathrm{g}}+\sigma_{\mathrm{o}}^{\mathrm{g}} \sqrt{G} U_{n}^{\mathrm{g}}, \quad \forall n \in \mathcal{N},
\end{aligned}
$$

where:

$$
\left(U_{n}^{\mathrm{e}}, U_{n}^{\mathrm{g}}\right)=\left\{\begin{array}{cc}
(+1,+1) & \text { with probability } \frac{\left(1+\rho_{\mathrm{o}}\right)}{4} \\
(+1,-1) & \text { with probability } \frac{\left(1-\rho_{\mathrm{o}}\right)}{4} \\
(-1,+1) & \text { with probability } \frac{\left(1-\rho_{\mathrm{o}}\right)}{4} \\
(-1,-1) & \text { with probability } \frac{\left(1+\rho_{\mathrm{o}}\right)}{4}
\end{array}\right.
$$

Once we obtain for each node the average electricity $\left(\bar{P}_{n}^{\mathrm{e}}\right)$ and gas $\left(\bar{P}_{n}^{\mathrm{g}}\right)$ prices, we generate 
scenario paths based on a scenario fan, which are referred to as subscenarios and indexed by $s \in \mathcal{S}$. This way, we obtain the electricity $\left(P_{n, s, m}^{\mathrm{e}}\right)$ and gas $\left(P_{n, s, m}^{\mathrm{g}}\right)$ spot prices for each subscenario $s \in \mathcal{S}$ and subperiod $m \in \mathcal{M}$ based on the average price within the node $n \in \mathcal{N}$. We assume that the short-term prices follow correlated Wiener processes with zero drift and are generated through the well-known stochastic differential equations of the two-dimensional correlated Wiener process [32], $\forall n \in \mathcal{N}, s \in \mathcal{S}, m^{\prime} \in \mathcal{M}$ :

$$
\begin{aligned}
& P_{n, s, m^{\prime}}^{\mathrm{e}}=\bar{P}_{n}^{\mathrm{e}}+\sum_{m=1}^{m^{\prime}} \sigma_{\mathrm{q}}^{\mathrm{e}} \epsilon_{n, s, m}^{\mathrm{e}} \\
& P_{n, s, m^{\prime}}^{\mathrm{g}}=\bar{P}_{n}^{\mathrm{g}}+\sum_{m=1}^{m^{\prime}}\left(\sigma_{\mathrm{q}}^{\mathrm{g}} \rho_{\mathrm{q}} \epsilon_{n, s, m}^{\mathrm{e}}+\sigma_{\mathrm{q}}^{\mathrm{g}} \sqrt{1-\rho_{\mathrm{q}}^{2}} \epsilon_{n, s, m}^{\mathrm{g}}\right)
\end{aligned}
$$

where $\sigma_{\mathrm{q}}^{\mathrm{e}}\left(\sigma_{\mathrm{q}}^{\mathrm{g}}\right)$ denotes the short-term electricity (gas) price volatility, $\rho_{\mathrm{q}}$ represents the shortterm price correlation, $\epsilon_{n, s, m}^{\mathrm{e}} \sim N(0,1)$, and $\epsilon_{n, s, m}^{\mathrm{g}} \sim N(0,1)$. While correlated GBMs do not take into account certain characteristics of commodity price dynamics (i.e., mean reversion or price jumps for the electricity price), these effects on modelling long-term average prices are negligible, and therefore GBMs are widely used in investment analysis [20]. Our aim is to generate scenarios that reflect uncertainties but that maintain characteristics that are likely to hold in the immediate future, such as the correlation between gas and electricity prices. Finally, the prices of electricity $\left(F_{n}^{\mathrm{e}}\right)$ and gas $\left(F_{n}^{\mathrm{g}}\right)$ futures contracts are calculated as the expected spot price at node $n \in \mathcal{N}$ multiplied by the risk premia ( $R^{\mathrm{e}}$ for electricity futures and $R^{\mathrm{g}}$ for gas futures) representing the persistent differences between the futures prices and their expected spot prices:

$$
\begin{aligned}
& F_{n}^{\mathrm{e}}=\left(\sum_{s \in \mathcal{S}} Q_{s}^{\mathrm{s}} \frac{1}{M} \sum_{m=1}^{M} P_{n, s, m}^{\mathrm{e}}\right)\left(1+R^{\mathrm{e}}\right) \\
& F_{n}^{\mathrm{g}}=\left(\sum_{s \in \mathcal{S}} Q_{s}^{\mathrm{s}} \frac{1}{M} \sum_{m=1}^{M} P_{n, s, m}^{\mathrm{g}}\right)\left(1+R^{\mathrm{g}}\right)
\end{aligned}
$$

